\title{
COVID-19 Incidence in Pakistan: Gender Disparity
}

\author{
Abdul Waris (iD ${ }^{1}$, Muhammad Ali ${ }^{1}$, Atta Ullah Khan ${ }^{2}$, Asmat Ali $^{3}$, Arshad Khan Bangash ${ }^{4}$ and Abdul \\ Baset (ii) ${ }^{5,}$ \\ ${ }^{1}$ Department of Biotechnology, Quaid-i-Azam University, Islamabad, Pakistan \\ ${ }^{2}$ Department of Biotechnology, University of Malakand, Chakdara, Pakistan \\ ${ }^{3}$ Centre for Human Genetics, Hazara University Mansehra, Mansehra, Pakistan \\ ${ }^{4}$ Department of Sociology, Bacha Khan University Charsadda, Charsadda, Pakistan \\ ${ }_{5}^{5}$ Department of Zoology, Bacha khan University Charsadda, Charsadda, Pakistan \\ "Corresponding author: Department of Zoology, Bacha khan University Charsadda, Charsadda, Pakistan. Tel/Fax: +92-3018535417, Email: drabdulbaset@bkuc.edu.pk
}

Received 2020 June 01; Revised 2020 June 06; Accepted 2020 June 06.

\begin{abstract}
Context: The COVID-19 outbreak was first experienced in China and rapidly spread to 212 countries/regions of the world, including Pakistan. It has affected both males and females, but the incidence is higher in males than in females worldwide.

Evidence Acquisition: According to the Ministry of National Health Services, Regulation, and Coordination of Pakistan, the female infection rate is much lower than the male infection rate in Pakistan ( $3.6 \%$ vs. 6.7\%, respectively). What are the main possible reasons that created gender disparity in COVID-19 incidence in Pakistan? We reviewed different factors that created gender disparity in COVID-19 Incidence in Pakistan.

Results: The biological differences, social, professional, religious, psychological factors, cultural, and lifestyle aspects have created a gender disparity in COVID-19 incidence in Pakistan.

Conclusion: This study mainly focused on the main possible reasons (mentioned above) that COVID-19 has affected men more than women worldwide, especially in Pakistan.
\end{abstract}

Keywords: Biological Differences, COVID-19 Incidence, Culture, Gender Disparity, Professionalism, Psychological Factors, Religion, Social Interaction

\section{Context}

The COVID-19 outbreak was first experienced in the city of Wuhan, a business hub of China, at the end of December 2019 (1). This disease is caused by a single-stranded RNA virus with a small genome of 26 - $32 \mathrm{~kb}$ that ranges from 65 to $125 \mathrm{~nm}$ in diameter (2). This virus belongs to the family Coronaviridae. Initially, Chinese researchers named the virus as 2019 novel coronavirus (2019-nCoV) (3). Later, the International Committee on Taxonomy of Viruses (ICTV) officially named the pathogen as severe acute respiratory syndrome coronavirus 2 (SARS-CoV-2) (4). On the same day, the World Health Organization (WHO) named the disease as coronavirus disease 2019 (COVID-19) (5). The disease was rapidly spread throughout China within a month, and according to the WHO, it has currently spread to 212 countries/areas/regions of the world, including Pakistan $(6,7)$.

Coronavirus disease 2019 is a very contagious disease. According to the WHO latest report on April 17 2020, there were 2,034,802 confirmed cases and 135,163 mortalities throughout the world. The United State of America (USA) had the highest number of positive cases and deaths, followed by France and Spain (7). On March 11, 2020, the WHO declared the COVID-19 outbreak a pandemic $(8,9)$. Currently, no antiviral drugs or vaccines are available against COVID-19. The work on vaccine development is in progress in the first stage of clinical trials (10). This disease is treated by different antiviral drugs and sometimes in combination with broad-spectrum antibiotics. The antiviral drug remdesivir has been suggested as a promising drug against COVID-19 (11).

Coronavirus disease 2019 has affected both males and females. However, the incidence is higher in males than in females worldwide. According to Remuzzi et al. (12), the death rates in Italy are $80 \%$ and $20 \%$ in males and females, respectively. In China, according to the studies by Huang et al. , Wang et al., and Chen et al., the male rate is higher than the female rate (13). In Pakistan, the female COVID-19 infection rate is much lower than the rate for males. According to the Ministry of National Health Services, Regulation, and Coordination, the Government of Pakistan, the female rate 
is lower than two-thirds of the male rate. The male and female rates in Pakistan are 6.7\% and 3.6\%, respectively (14). There are different possibilities for why COVID-19 affects males more than females. In this study, we mainly focused on delineating the main possible reasons that COVID-19 has affected men more than women, especially in Pakistan.

\section{Evidence Acquisition}

The narrative method was used to review the relevant literature. The research question addressed in this study was as follows:

"What are the main possible reasons that caused gender disparity in COVID-19 Incidence in Pakistan?" After raising the question, different electronic English databases such as Google, Google Scholar, Wiley online library, Scopus, Science Direct, Web of Science, and PubMed were searched and explored by four authors using appropriate keywords such as biological Differences, COVID-19 Incidence, gender disparity, psychological factors, professionalism, social, culture, and religious factors, etc. In this article, we reviewed different factors that created gender disparity in COVID-19 Incidence in Pakistan.

\section{Results}

\subsection{Biological Differences}

The immune system and its coordinated responses are shaped by a variety of endogenous and exogenous factors, modulators, and challenges. Sex differences play a central role in determining how the male and female immune systems are regulated and respond to stimuli (15). One of the most important differences is that females have stronger innate, humeral, and cell-mediated immune responses than males, which leads to the acceleration of clearing or decreasing the viral/antigen/pathogen load. In the medical field, sex refers to the biological and genetic status of an organism, such as whether it has the XX or XY genotype. Both of these factors play an important role (16).

The different sexes (male and female) respond differently to viral pathogenesis. Women have greater antiviral, inflammatory, and cellular immune responses. Different human illnesses affect males and females differently. Susceptibility to viral infections is much lower in females than in males because females typically mount high immune responses (17). Generally, both infection severity and rate of infected individuals are less in females than in males for fungal, bacterial, viral, and other parasitic diseases. These immune responses to different viruses can vary due to hormone concentrations affected by natural fluctuations over estrous or menstrual cycles, during pregnancy or contraception use. The mechanisms mediating sex differences in response to viral infections are being examined empirically in both laboratory and clinical settings (18). In animal models (mice), picornavirus-induced diseases showed a sex bias, with less disease in females and worse disease in males and pregnant females. In the West Nile virus (WNV), hantaviruses, coxsackievirus infections, and paramyxovirus infections, the female shows high response and mounts a stronger immune response than the male. The more effective responses by females than males to viruses are due to differences in hormone concentrations $(17,18)$. Therefore, hormones play a vital role in fighting viruses. In addition, genetic differences, sex hormones, and sex differences in immunity (innate, humoral, and cell-mediated) also play important roles. These mechanisms are likely to be important in the case of COVID-19, as well. Due to the robust immune response of females, COVID-19 affects males more than it does females.

\subsection{Immune System}

Infectious diseases have been a major obstacle to human life for much of evolutionary history. The response to that threat has been the increasing immunity. Indeed, a strong innate and adaptive immune response is so fundamental to human survival that we might assume that the evolved genotypes and consequent phenotypes, including body temperature, would be fairly invariant (19). In general, females appear to have a stronger and more stable immune system across species. This helps them better handle vaccines and infections (20). Maintaining immune defense effectively adopts maternal immunological conditions and improves with fetal growth and development at different gestation stages (20). Men may not experience exaggerated symptoms, but they have poor immune responses to respiratory viruses, resulting in more morbidity and mortality than in women (21). According to the ovulatory shift hypothesis, in the pre-ovulatory phase of the menstrual cycle, the female is socially dominant, and underlying health is highest (22). Some researchers have said this difference in sex-specific health may be due, at least in part, to a tiny piece of genetic material called microRNAs. In cells, the main function of microRNAs is to shut off specific genes, showing that microRNAs in the chromosomes will provide women with an advantage over males concerning the immune system. Women are more resistant to bacterial and viral infections, a difference associated with higher levels of antibodies and greater activation of T cells (23). Women mount more adaptive humoral and cellular immune responses than men (24). Women produce higher antibody responses with higher basal and 
post-vaccination IgG rates and higher B cell counts in response to viral infections (25). In addition, nonspecific markers of cell-mediated immunity, such as the proliferation of mitogenic lymphocytes and wound healing, are enhanced in females (26). Increased immune reactogenicity among women is thought to make them more resistant to infectious diseases but also leads to an increased incidence of female autoimmunity (23).

\subsection{Psychological Differences}

It is thought that psychologically, males are highly stronger than females, but this is not true. In the Pakistani population, females are psychologically much stronger than males. Psychologically strong women have some characteristics; for example, strong women do not compare themselves with others. They do not need to know what others are doing to make themselves feel good. Strong women do not think about what other people do (27). They are realistic, practical, confident, honest, and loyal in every relationship; they are straightforward and know how to deal. In addition, they are strong and not afraid of any unfavorable situation. They can handle and combat strong and harsh conditions (28). Coronavirus disease 2019 is an infection that affects not only the respiratory system but also creates a psychological problem. Currently, most people fear this infection and worry that if they become infected, it may lead to death, so they are psychologically ill all the time. In Pakistan, psychologically sick people are mostly men. Females do not think like that, and they are highly stable and psychologically strong (29). This may be one possible reason why females are less affected in Pakistan.

\subsection{Smoking}

Smoking causes heart disease, diabetes, lung disease, cancer, stroke, and chronic obstructive pulmonary disease. According to the WHO, more than eight million people worldwide die due to smoking every year. Of these, seven million deaths occur due to direct smoking, while 1.2 million deaths are due to passive smoking. Although $80 \%$ of smokers belong to middle or lower economic classes, Pakistan places in the top 15 countries with most tobacco consumption, and it has health-related issues due to this high rate of consumption (30). According to the Pakistan Civil Society Alliance for Tobacco Control, currently, about 19.1\% of the Pakistani population consume tobacco in various forms. Of these, about 31.8\% are men, and 5.8\% are women. According to the American Lung Association, the rates of smoking are $13.5 \%$ and $17.5 \%$ in men and women in the US, respectively. Furthermore, smoking kills about 202,000 women in the US only (31). In China, the female smoker percentage is $27.3 \%$, and in Italy, Spain, and France, the percentages are $19.8 \%, 27.4 \%$, and $33 \%$ (increased from $28 \%$ ), respectively. Therefore, if we compare these countries with Pakistan regarding female smoking, the percentage is much lower in Pakistan than in all of these countries (30). Coronavirus disease 2019 highly affects the lungs and respiratory system (32). Smokers' lungs and respiratory systems are already affected by tobacco, and thus when COVID-19 infects these individuals, the infection can become severe and may lead to death. This is one of the main reasons that females are less affected in Pakistan than in the rest of the world. The percentage of female smokers is much less than that for males. That is why the rate of COVID-19 infection is higher in males than in females.

\subsection{Traditional Scarves}

A traditional scarf is a piece of fabric that covers the head, neck, and face. In some countries, women do not use a scarf for health care to protect their skin from sun rays, but it is considered part of female religious dress. Most of the Muslim women wear scarves according to religious practice if they leave homes. In Pakistan, wearing scarves is a religious action, as well as part of the national cultural dress. The majority of Pakistani women wear scarves when they leave homes for employment, shopping, or other purposes. According to a survey conducted by the University of Michigan Population Studies Center, more than 32\% of Pakistani women favor scarves (33). Currently, according to the WHO guidelines about basic protective measures against the COVID-19 outbreak, one should use a mask to cover his face, nose, and mouth when out of the home (30). For the same purpose, however, Pakistani women already use scarves. This may be a very important reason why Pakistani females are less affected by COVID-19 than Pakistani males, as well as females of other countries where males and females are affected almost equally.

\subsection{Carefulness and Carelessness}

In the current scenario, across the whole country, the percentage of affected men is higher than that of women because women are less susceptible than men to healthrelated issues. Some studies have shown that the variation in the prevalence and severity of COVID-19 disease is associated with sex, and smoking is associated with higher expression of SARS-CoV-2. It may also be because of the higher percentage of infected men (34). A study using single-cell sequencing found that ACE2 expression was more prevalent in Asian men, which could be a reason why COVID-19 is higher among men than among women (20). This sexual 
predisposition may be correlated with a much higher rate of affected men than women due to exposure and carelessness. Mostly, Pakistani men work in shops, restaurants, and industries and do not take precautions to protect themselves from this pandemic; but women, on the other hand, are mostly homemakers who are less vulnerable and prone to protecting their health, which is the main reason why the infection level is higher in men and lower in women.

People suffering from COVID-19 will face moderate breathing problems, although older people or those who have other medical issues such as cardiac disease or diabetes are more likely to develop a serious illness (35). The actual cause of spreading COVID-19 is through droplets of saliva from the mouth and nose. When an infected person sneezes or coughs, the germs in droplets are easily transmitted to other individuals. Hence, special care is required while sneezing or coughing (36). The best way provided by the WHO to avoid the COVID-19 spread is to wash hands frequently, maintain social distance, and avoid crowds and other gatherings (7). The Pakistani government is facing lots of challenges to fight against this pandemic. The government and the police are working together to keep the citizens safe from this disease (37). The Pakistan International Airline (PIA) suspended flight operations from China in January. Also, the Pakistan Civil Aviation Authority (CAA) introduced screening measures at airports for passengers traveling back from international and national flights. The government advised the public to stay at home and avoid mass gatherings, handshaking, and hugging as precautionary measures. Schools and universities were closed by March 5 (38). The parade for March 23 , which is one of the most promoted events, was canceled with all public events and gatherings. Also, a proceeding of the Senate was postponed for two weeks. Pakistan closed its shared borders for two weeks, which were reopened later for food transportation, whereas pedestrian movement remains suspended. Food delivery services and takeout are closed until further notice. Strict security measures are taken by the police to avoid further social contact. For some reason, however, Pakistani men citizens do not take this pandemic seriously. Even after awareness and announced precautions, few men use masks or gloves. Huge crowds and gatherings are being recorded at supermarkets and department stores. Due to this pandemic, merchants are profiting by selling masks and sanitizers at a high rate. Citizens were advised to maintain distance, avoid going out, and wash their hands and face as many times as possible. Due to carelessness, however, people are still suffering from such unwise behaviors and do not take this threat seriously. During this pandemic, Pakistan, as an underdeveloped country, can face serious consequences, including lower availability of medication and high charges for hospitalization; not everyone can afford these treatments. Additionally, even after such measures and laws, people are roaming around casually; this can cause a high rate of COVID-19 cases. Since we know that a man will care less for his work, the above sentence brings to mind a man less caring for certain things, which might be harmful. These people do not show responsibility or concern for their lives and their surroundings in Pakistan. For these reasons, men may bring the virus home and can harm their families through a lack of care.

\subsection{Professionalism and Social Interaction}

In society, being a professional, which might be a basic component of society and the environment, has been practiced since life arose on the planet. The main professionals, including engineers, doctors, students, teachers, laborers, farmers, and skilled people around us interacting with each other daily, tend to be males in Pakistan. In the case of COVID-19, however, these professionals mostly leave their homes and are exposed to the virus in their surroundings. Laborers and farmers who have no facilities at their work may easily contract the virus from their surroundings. The outbreak of the novel COVID-19 increasingly affects certain industries and demographic groups excessively (39). However, individuals also get closer to each other through social interaction. The interaction is based on two conditions: contact and communication. Society is necessary for everyone, and for men, it is difficult to live in isolation instead of in groups. As a member of the Pakistani society, males are expected to attend certain matters, such as funerals, etc. By interacting with each other, they live their social life with ease. It may lead to becoming infected very fast, in the case of the COVID-19 outbreak. The infection rate is higher for males than for females due to exposure to the virus because of the male community interacting with each other everywhere due to professional and social interactions in Pakistan. In many cases, they do not know the proper measures to avoid the transmission of the virus or use personal protective equipment to stay safe from the viral infection (40). Observations have shown that social mobilization plays an important role in the spread of the outbreak. To mitigate the rapid spread of COVID-19 through the local community, the jurisdictions have implemented policies for interventions and public health measures to minimize the spread of COVID-19 (41).

\subsection{Laboring}

The lifestyle of laborers is not sufficient to keep them safe from exposure to any type of pathogen or harmful ma- 
terials. Due to COVID-19, the workplaces are not safe. Workers are stressed in their workplaces and worried about being infected by COVID-19. It is time-taking to implement social distancing measures and restructure an organization's culture and the local context of society as the situation changes. The COVID-19 outbreak surged to various countries increasingly. The recommencement of official duty and social activities may cause a threat of another wave of COVID-19 cases worldwide. It is an insidious infectious disease that may bring more serious outcomes with genetic evolution before vaccination and treatment are initiated. Therefore, workplace safety involving business and employers in society is the key to success in the battle of the COVID-19 pandemic (41). In the case of Pakistan, about $97 \%$ of male laborers perform duties. They are not safe due to the lack of proper guidelines because no one can go home due to poverty, while the labor community will never like to sit in their homes to stop the pandemic. The government needs to ensure their daily needs and provide basic support to stop the outbreak from spreading. For these reasons, the spread of the virus may increase in the labor community in Pakistan.

\subsection{Staying at Home}

Over half of the Pakistani women are homemakers and stay at home, which reduces the risk of infection because domestic exposure to this pandemic is limited, as the temperature in the kitchen is above the room temperature (39). According to the statistics from the Government of the Hong Kong Special Administrative (HK) working population, the recruited sample included more women from the occupational group of blue-collar workers (service workers/sales/craft workers, plat/machine operators and assemblers, elementary workers, and others) $(42,43)$. Women seem to have more perceived influence than men, which may be a major reason why COVID-19 affects more men than women. Many women stay at home or work in a place where the chances of exposure are more limited than in a place where most men do their jobs. Staying at home is one of the WHO's coronavirus disease (COVID-19) advice for the public, and the majority of the women staying at home around the country indicate that they are homemakers, which is a big reason why such women remain unaffected.

\subsection{Washing and Cleaning}

Washing and cleaning are some of the recommendations to prevent COVID-19 infection and spread. Attempts to enhance hand hygiene and other infection prevention behaviors through education and awareness have minimal and short-term effects, particularly in acute healthcare settings (40). Hygiene plays a role in preventing infectious diseases; thus, people who wash and clean themselves and their clothes and houses have little chance of being exposed to this pandemic. Handwashing and the use of sanitizers are crucial components in substantially reducing the transmission of infectious diseases, such as COVID-19. The single most effective step to avoid nosocomial infection remains hand hygiene, either by handwashing or hand disinfection (44). Therefore, cleaning and washing are some of the reasons why COVID-19 has less affected women in Pakistan, because the majority of women around the country are active in cleaning and washing their homes, their clothes, and themselves.

\subsection{Working in the Kitchen}

Higher temperatures considerably decrease the SARS coronavirus spread, which means women working in the kitchen may not be affected or are less likely to be contaminated with COVID-19. That higher temperature decreases the virus transmission suggests that people involved in the kitchen have fewer chances for COVID-19 infection. Some researchers have also confirmed that SARS-CoV-2 infectivity lost after 15 minutes at $56^{\circ} \mathrm{C}(45,46)$. The virus does not replicate outside a living host, but the infectious virus may survive in a contaminated environment, and the persistence of viable viruses is markedly affected by temperature. Most women do their kitchen work in households in Pakistan, which is one of the possible reasons why the proportion of COVID-19 infection is lower in women.

\subsection{Worship}

Worship may be one of the possible routes of transmission of the virus among populations because there are many religions worldwide, and they have unique ways to perform their worship activities in the context of crowds, with males and females together. In all religions, flexibility is possible if worship activities are late and do not take place on time. Muslims have separate mosques for males and females or separate sites in the same mosque worldwide. In Pakistan, however, most mosques are only for males, and about $99 \%$ of females perform worship at their homes (47). That is one of the possible reasons why females have a lower rate of COVID-19 than males.

\section{Conclusions}

Coronavirus disease 2019 has affected both males and females, but the infection rates of males are higher than 
those of females worldwide. In Pakistan, the incidence in females is much less than two-thirds (3.6\% vs. 6.7\%) of the incidence in males. There are many factors involved, e.g., smoking, traditional scarves, biological and immune differences, psychological factors, lifestyle, and behavioral differences, which make females less affected than males. In the present scenario, females are caring, social, and psychologically stronger, which may be possible reasons for gender disparity in COVID-19 infection in Pakistan.

\section{Footnotes}

Authors' Contribution: Abdul Waris and Atta Ullah Khan searched the databases and retrieved the relevant literature. Abdul Baset arranged and compiled the format and handled the correspondence. Abdul Waris Asmat Ali, , Arshad Khan Bangash, and Muhammad Ali selected the literature and finalized the manuscript. All authors read and approved the final manuscript.

Conflict of Interests: The authors declare no conflict of interest.

Funding/Support: The authors received no specific funding for this work.

\section{References}

1. Wu JT, Leung K, Bushman M, Kishore N, Niehus R, de Salazar PM, et al. Estimating clinical severity of COVID-19 from the transmission dynamics in Wuhan, China. Nat Med. 2020;26(4):506-10. doi: 10.1038/s41591-020-0822-7. [PubMed: 32284616]. [PubMed Central: PMC7094929].

2. Kaul D. An overview of coronaviruses including the SARS-2 coronavirus - Molecular biology, epidemiology and clinical implications. Curr Med Res Pract. 2020;10(2):54-64. doi: 10.1016/j.cmrp.2020.04.001.

3. Zhu N, Zhang D, Wang W, Li X, Yang B, Song J, et al. A novel coronavirus from patients with pneumonia in China, 2019. $N$ Engl J Med. 2020;382(8):727-33. doi: 10.1056/NEJMoa2001017. [PubMed: 31978945]. [PubMed Central: PMC7092803].

4. Qf the International Coronaviridae Study Group. The species Severe acute respiratory syndrome-related coronavirus: Classifying 2019$\mathrm{nCoV}$ and naming it SARS-CoV-2. Nat Microbiol. 2020;5(4):536-44. doi:10.1038/s41564-020-0695-z. [PubMed:32123347]. [PubMed Central: PMC7095448].

5. World Health Organization. Coronavirus disease 2019 (COVID-19): Situation report. 2020

6. Curley M, Thomas N. Human security and public health in Southeast Asia: The SARS outbreak. Aust J Int Aff. 2010;58(1):17-32. doi: $10.1080 / 1035771032000184737$.

7. World health Organization(WHO). Coronavirus disease (COVID-19) pandemic. 2020, [cited 2020 Apr 17]. Available from: https://www. who.int/ emergencies/diseases/novel-coronavirus-2019.

8. Jiang F, Deng L, Zhang L, Cai Y, Cheung CW, Xia Z. Review of the clinical characteristics of coronavirus disease 2019 (COVID-19). J Gen Intern Med. 2020;35(5):1545-9. doi: 10.1007/s11606-020-05762-w. [PubMed: 32133578]. [PubMed Central: PMC7088708].

9. Ebrahim SH, Ahmed QA, Gozzer E, Schlagenhauf P, Memish ZA Covid-19 and community mitigation strategies in a pandemic. BMJ. 2020;368:m1066. doi: 10.1136/bmj.m1066. [PubMed: 32184233].
10. Abdul W, Muhammad A, Atta Ullah K, Asmat A, Abdul B. Role of nanotechnology in diagnosing and treating COVID-19 during the pandemi. Int J Clin Virol. 2020;4(1):65-70. doi: 10.29328/journal.ijcv.1001017.

11. Wang M, Cao R, Zhang L, Yang X, Liu J, Xu M, et al. Remdesivir and chloroquine effectively inhibit the recently emerged novel coronavirus (2019-nCoV) in vitro. Cell Res. 2020;30(3):269-71. doi: 10.1038/s41422-020-0282-0. [PubMed: 32020029]. [PubMed Central: PMC7054408].

12. Remuzzi A, Remuzzi G. COVID-19 and Italy: What next? Lancet. 2020;395(10231):1225-8. doi: 10.1016/s0140-6736(20)30627-9.

13. Wu C, Chen X, Cai Y, Xia J, Zhou X, Xu S, et al. Risk Factors Associated With Acute Respiratory Distress Syndrome and Death in Patients With Coronavirus Disease 2019 Pneumonia in Wuhan, China. JAMA Intern Med. 2020. doi: 10.1001/jamainternmed.2020.0994. [PubMed: 32167524]. [PubMed Central: PMC7070509].

14. Government of Pakistan; Ministry of National Health Services. Novel coronavirus. 2020. Available from: http://www.nhsrc.gov.pk/.

15. Oertelt-Prigione $S$. The influence of sex and gender on the immune response. Autoimmun Rev. 2012;11(6-7):A479-85. doi: 10.1016/j.autrev.2011.11.022. [PubMed: 22155201].

16. Klein SL, Jedlicka A, Pekosz A. The Xs and Y of immune responses to viral vaccines. Lancet Infect Dis. 2010;10(5):338-49. doi 10.1016/S1473-3099(10)70049-9. [PubMed: 20417416]. [PubMed Central: PMC6467501].

17. Fish EN. The X-files in immunity: sex-based differences predispose immune responses. Nat Rev Immunol. 2008;8(9):737-44. doi: 10.1038/nri2394. [PubMed: 18728636]. [PubMed Central: PMC7097214].

18. Klein SL, Flanagan KL. Sex differences in immune responses. Nat Rev Immunol. 2016;16(10):626-38. doi: 10.1038/nri.2016.90. [PubMed: 27546235].

19. Ness RB. The consequences for human reproduction of a robust inflammatory response. Q Rev Biol. 2004;79(4):383-93. doi: 10.1086/426089. [PubMed: 15669771].

20. Zhao Y, Zhao Z, Wang Y, Zhou Y, Ma Y, Zuo W. Single-cell RNA expression profiling of ACE2, thereceptor of SARS-CoV-2. BioRxiv. 2020. doi: 10.1101/2020.01.26.919985.

21. Sue K. The science behind "man flu". BMJ. 2017;359:j5560. doi: 10.1136/bmj.j5560. [PubMed: 29229663].

22. Dixson BJW, Lee AJ, Blake KR, Jasienska G, Marcinkowska UM. Women's preferences for men's beards show no relation to their ovarian cycle phase and sex hormone levels. Horm Behav. 2018;97:137-44. doi: 10.1016/j.yhbeh.2017.11.006. [PubMed: 29129624].

23. Fischinger S, Boudreau CM, Butler AL, Streeck H, Alter G. Sex differences in vaccine-induced humoral immunity. Semin Immunopathol. 2019;41(2):239-49. doi: 10.1007/s00281-018-0726-5. [PubMed: 30547182]. [PubMed Central: PMC6373179].

24. Markle JG, Fish EN. SeXX matters in immunity. Trends Immunol 2014;35(3):97-104. doi: 10.1016/j.it.2013.10.006. [PubMed: 24239225].

25. Flanagan KL, Fink AL, Plebanski M, Klein SL. Sex and gender differences in the outcomes of vaccination over the life course. Annu Rev Cell Dev Biol. 2017;33:577-99. doi: 10.1146/annurev-cellbio-100616-060718. [PubMed: 28992436].

26. Maman K, Zollner Y, Greco D, Duru G, Sendyona S, Remy V. The value of childhood combination vaccines: From beliefs to evidence. Hum Vaccin Immunother. 2015;11(9):2132-41. doi:10.1080/21645515.2015.1044180. [PubMed: 26075806]. [PubMed Central: PMC4635899].

27. Qualities of strong women. 2020, [cited 2020 Apr 15]. Available from: https://www.brightside.me/inspiration-psychology/13-tipsthat-can-help-you-become-a-stronger-woman-613660/.

28. Forbes: Mentally strong women. 2020, [cited 2020 Apr 14]. Available from: https://www.forbes.com/sites/amymorin/2020/02/11/7things-mentally-strong-women-believe/\#73bce4c41b4e. 
29. The Guardian. Fear of Covid-19 is a mental contagion - and that's something we can fight. 2020, [cited 2020 Apr 15]. Available from: https://www.theguardian.com/commentisfree/2020/mar/26/fearof-covid-19-is-a-mental-contagion-ben-okri.

30. WHO. Tobacco-World Health Organization. 2020, [cited 2020 Apr 14] Available from: https://www.who.int/news-room/fact-sheets/detail/ tobacco.

31. Pakistan civil society alliance for tobacco control. 2020, [cited 2020 Apr 14]. Available from: https://hdfpk.com/pakistan-civil-societyallianc-2/.

32. Tian S, Hu W, Niu L, Liu H, Xu H, Xiao SY. Pulmonary pathology of early-phase 2019 novel coronavirus (COVID-19) pneumonia in two patients with lung cancer. J Thorac Oncol. 2020;15(5):700-4. doi:10.1016/j.jtho.2020.02.010. [PubMed:32114094]. [PubMed Central: PMC7128866].

33. Merriam-webster. Scarf. 2020, [cited 2020 Apr 14]. Available from: https://www.merriam-webster.com/dictionary/scarf.

34. Cai H. Sex difference and smoking predisposition in patients with COVID-19. Lancet Respir Med. 2020;8(4). e20. doi: 10.1016/S2213 2600(20)30117-X. [PubMed: 32171067]. [PubMed Central: PMC7103991].

35. Zhou F, Yu T, Du R, Fan G, Liu Y, Liu Z, et al. Clinical course and risk factors for mortality of adult inpatients with COVID-19 in Wuhan China: A retrospective cohort study. Lancet. 2020;395(10229):1054-62. doi: 10.1016/s0140-6736(20)30566-3.

36. Ge ZY, Yang LM, Xia JJ, Fu XH, Zhang YZ. Possible aerosol transmission of COVID-19 and special precautions in dentistry. J Zhejiang Univ Sci B. 2020;21(5):361-8. doi: 10.1631/jzus.B2010010. [PubMed: 32425001] [PubMed Central: PMC7089481].

37. Waris A, Atta UK, Ali M, Asmat A, Baset A. COVID-19 outbreak: Current scenario of Pakistan. New Microbes New Infect. 2020;35:100681. doi: 10.1016/j.nmni.2020.100681. [PubMed: 32322403]. [PubMed Central: PMC7171524].

38. The News international. 2020. Available from: https://www.thenews com.pk/latest/628643-pakistani-schools-madrassas-universities- to-remain-shut-till-april-5-amid-coronavirus-scare.

39. Chaganti S, Graves E, Higgins A, Mattingly M, Savage S, Tonsberg C. The effects of the novel coronavirus pandemic on service workers in new England. Fed Reserve Bank Boston Commun Develop Issue Brief. 2020;31.

40. Lunn PD, Belton CA, Lavin C, McGowan FP, Timmons S, Robertson DA. Using behavioral science to help fight the coronavirus. J Behav Publ Adm. 2020;3(1). doi:10.30636/jbpa.31.147.

41. Ustun TB, Chatterji S, Kostanjsek N, Rehm J, Kennedy C, EppingJordan J, et al. Developing the World Health Organization Disability Assessment schedule 2.0. Bull World Health Organ. 2010;88(11):81523. doi: 10.2471/BLT.09.067231. [PubMed: 21076562]. [PubMed Central: PMC2971503].

42. Wong J, Goh QY, Tan Z, Lie SA, Tay YC, Ng SY, et al. Preparing for a COVID-19 pandemic: A review of operating room outbreak response measures in a large tertiary hospital in Singapore. Can J Anaesth. 2020;67(6):732-45. doi: 10.1007/s12630-020-01620-9. [PubMed: 32162212]. [PubMed Central: PMC7090449].

43. Wong ELY, Ho KF, Wong SYS, Cheung AWL, Yeoh EK. Workplace safety and coronavirus disease (COVID-19) pandemic: Survey of employees. Bull World Health Organ. 2020. doi: 10.2471/blt.20.255893.

44. Pittet D, Hugonnet S, Harbarth S, Mourouga P, Sauvan V, Touveneau $S$, et al. Effectiveness of a hospital-wide programme to improve compliance with hand hygiene. Infection control programme. Lancet. 2000;356(9238):1307-12. doi: 10.1016/s0140-6736(00)02814-2. [PubMed: 11073019].

45. Bukhari Q, Jameel Y. Will coronavirus pandemic diminish by summer? SSRN Electron J. 2020. doi: 10.2139/ssrn.3556998.

46. Chan KH, Peiris JS, Lam SY, Poon LL, Yuen KY, Seto WH. The effects of temperature and relative humidity on the viability of the SARS coronavirus. Adv Virol. 2011;2011:734690. doi: 10.1155/2011/734690. [PubMed: 22312351]. [PubMed Central: PMC3265313]

47. Encyclopedia Britannica. Islam. 2020, [cited 2020 Apr 14]. Available from: https://www.britannica.com/topic/Islam. 